\title{
ENERGY MANAGEMENT ALgORITHMS IN SMART GRIDS: STATE OF THE ART AND EMERGING TRENDS
}

\author{
Joelle Klaimi $^{1,2}$,Rana Rahim-Amoud ${ }^{1,3}$,Leila Merghem-Boulahia ${ }^{2}$ and Akil Jrad ${ }^{1,3}$ \\ ${ }^{1}$ EDST, LaSTRe, Lebanese University, Lebanon. \\ ${ }^{2}$ ICD/ERA (UMR CNRS 6281), Troyes University of Technology, France. \\ ${ }^{3}$ Faculty of sciences, Lebanese University, Lebanon.
}

\begin{abstract}
The electric grid is radically evolving into the smart grid, which is characterized by improved energy efficiency of available resources. The smart grid permits interactions among its computational and physical elements thanks to the integration of Information and Communication Technologies (ICTs). ICTs provide energy management algorithms and allow renewable energy integration and energy price minimization. Given the importance of renewable energy, many researchers developed energy management (EM) algorithms to minimize renewable energy intermittency. EM plays an important role in the control of users' energy consumption and enables increased consumer participation in the market. These algorithms provide consumers with information about their energy consumption patterns and help them adopt energy-efficient behaviour. In this paper, we present a review of the state of the energy management algorithms. We define a set of requirements for EM algorithms and evaluate them qualitatively. We also discuss emerging tools and trends in this area.
\end{abstract}

\section{KEYWORDS}

Smart grids, Energy management, Renewable resources, Storage systems, Multi-agent systems

\section{INTRODUCTION}

There is a growing worldwide interest in the evolution of the smart grid [1], a modern power grid that supports bidirectional communication between energy providers and consumers for finegrained metering, control, and feedback. One of the key features of the smart grid is enhancing energy efficiency and manageability of available resources [2]. According to the European Commission Task Force on Smart Grid, the smart grid is defined as an electricity network that can intelligently integrate the action of all users connected to it - generators, consumers and those that do both - in order to ensure economically efficient and sustainable power system with low losses, high level of quality, security of supply and safety [3]. In fact, fossil fuels represent the major energy resources in most countries, these resources release toxic gas that have severe consequences on the habitats and affect human health [4]. Furthermore, fossil resources are exhaustible and no longer available once used. To offer a greener and a cheaper solution, the smart grid incorporates the distributed renewable resources such as wind, solar and hydroelectric. The renewable resources reduce fuel consumption and $\mathrm{CO}_{2}$ emissions. Moreover, the integration of distributed renewable resources in the smart grids minimizes system losses and increases the reliability, efficiency and security of electricity supply to consumers [5, 6]. (1) These resources are inexhaustible. Even (1), they are however non-scheduled resources because they depend on weather and natural phenomena which makes it complex to balance supply and demand [7]. In

DOI: 10.5121/ijaia.2016.7403 
this context, the smart grid helps consumers (residential, commercial, etc.) to be energy suppliers; they are then called prosumers. In addition, this new grid permits the two-way flow of information and electricity between consumers and electric power companies. Figure 1 shows this two-way flow in all communication infrastructures in smart grid architecture. These infrastructures include home area networks (HANs), business area networks (BANs), neighborhood area networks (NANs), data centers, and substation automation integration systems [8].

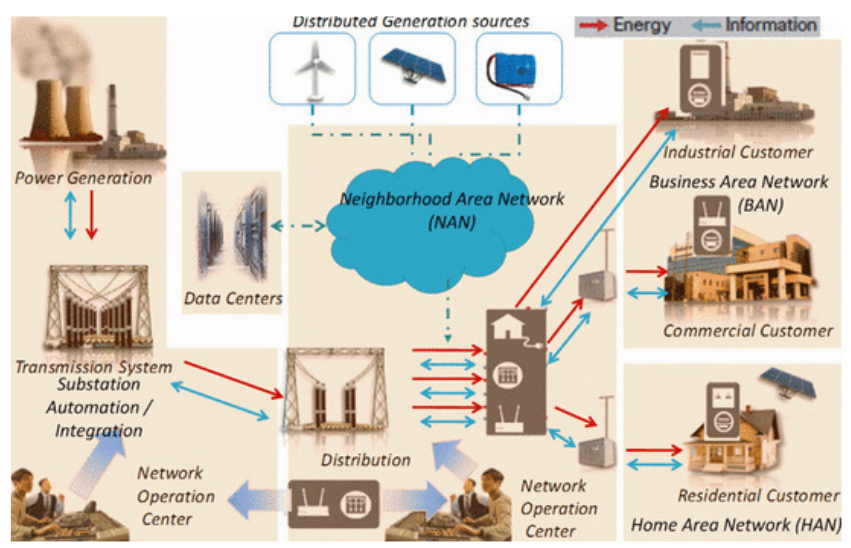

Figure 1 Illustration of smart grid communication network [8]

The two-way communication in the smart grid architecture is responsible for transmitting power grid sensing and measuring status, as well as the control messages [9] which helps consumers to control their energy usage [10]. In order to control the grid energy usage and to give utility companies the access to the requested information, smart grid includes new smart entities like smart meters [11]. Entities communication can be wired (power line communication, etc.), or wireless (cellular networks, sensor networks, etc.) [12]. To provide near real-time information to utilities and end users, a smart grid integrates distributed computing and communication systems. In addition, this smart grid introduces several technologies such as information and communication technologies to ensure reliability, demand management, storage, distribution and transport of electrical energy [13]. Facing the necessity of renewable resources integration, energy management algorithms represent a great solution to make a decision about power delivering in efficient ways. In order to reduce consumers' energy bill, energy management provides autonomous actions in controlling different electrical grid subsystems (energy generation, distribution and consumption).

In the literature, we can find many definitions of energy management. Based on the definitions given in $[14,15,16,17,18,19]$, the energy management can be defined as a set of strategies and functions that can adjust and optimize the energy use. These set of functions increase the energy efficiency and coordinate the energy resources. It is the process of observing, controlling and conserving electricity usage in a building, a neighborhood, etc. Energy management should be able to optimize costs and to minimize the risk of loss of production excess.

To make intelligent decisions about energy management functions, multi-agent algorithms have been adopted by several researchers. The Multi-Agent System (MAS) is a paradigm used when the problem to resolve is complex. The MAS is an important tool for self-control in widely distributed systems whose characteristics are very dynamic [20]. A MAS is composed of a set of autonomous and intelligent entities called agents deployed in a shared environment and acting intelligently upon that environment, these agents interact and cooperate in order to reach a 
specific objective [21]. Each agent in MAS has a degree of smartness depending on storage and management role and/or functions [22].

In order to meet consumers' needs, the smart grid exchanges a huge amount of expensive data [23]. In this regard, cloud computing is a response for the vast data exchange in the smart power grid. Cloud computing presents many advantages in on-demand self-service, ubiquitous network access and location independent resource pooling. Furthermore, cloud providers own their immense data centers responsible for computation, storage capacities, applications and services $[23,24]$. As a brief definition, the cloud computing is a procedure to share resources. By using the cloud infrastructure, users can access their applications anytime and from anywhere through a device connected to the network [25]. Cloud computing discharges the users from a number of constraints. However, the cloud computing infrastructure is not suitable to latency-sensitive applications. This fact encourages researchers to explore fog computing. Fog computing is the extension of the cloud computing paradigm to the edge of the network. It presents several advantages comparing to the cloud computing: low latency, wide-spread geographical distribution, very large number of nodes, etc. [26, 27, 28]. In fact, cloud and fog computing architectures have been studied by many researchers that they could have a role in the smart grid energy management.

The purpose of this article is to present some energy management algorithms used in smart grids or microgrids. The rest of this paper is organized as follows. We present an overview of demand response programs and energy storage in section 2 . An explanation of multi-agent concept, cloud computing and fog computing paradigm will be given in section 3. In section 4 we present some algorithms of energy management in smart grids and microgrids. We conclude our paper in the section 5 .

\section{ENERGY MANAGEMENT REQUIREMENTS}

The introduction of renewable resources has generated problems of intermittency and irregularity. The demand response is necessary for the stability of the electricity network operation. Utilities have to offer tariffs that motivate consumers to save energy and/or shift loads to off-peak periods. Furthermore, buffering and storing energy should be a solution for renewable energies problems. In 2012, Sofana et al. and Law et al. published an extensive review of demand response and energy management modeling and feedback techniques [29, 30]. More recently, Vardakas et al. [31] and Deng et al. [32] offered a detailed review of feedback methods for energy management and demand response in smart grid architecture. In the next subsection, the demand response programs in the smart grids will be defined.

\subsection{Demand Response Programs}

The Demand Response (DR) is an opportunity for the consumers' participation in electricity markets. The smart grids can give an important support for the integration of demand response [33]. Based on [34, 35, 36], the DR consists in changing the normal electrical use of end users in response to price changes. The DR has an important role to play in electricity market, it can be a solution to minimize the demands especially in peak hours or when system reliability is jeopardized. In other words, this DR program aims to smooth consumption in peak hours and reduce the cost of energy by shifting demands from peak hours to off-peak hours. Consumers who participate to the DR have two ways to change their electricity usage [34, 36]: (1) reduce energy consumption during critical peak periods when prices are high without changing their consumption during off-peak hours, this way involves a temporary loss of comfort. (2) Shift some of the peak demand operations to off-peak periods. Moreover, there are different classifications of 
the DR programs that can be found in literature and can be divided into three categories: the ratebased or price DR programs, the incentive or event-based DR programs and the demand reduction bids [34]. Firstly, in the rate-based DR program, DR is implemented over utility tariffs in the markets according to variable electricity prices in order to motivate consumers to adjust their consumption patterns and to react to the fluctuations in the electricity prices. In fact, consumers pay a high price during high peak periods and a low price during off-peak periods [34]. Secondly, the event-based DR program rewards all consumers who minimize their consumption upon request. Additionally, this program can be a response to many conditions like local or regional grid congestion, system economics, or operational reliability requirements, local or system temperature, etc. [34]. Thirdly, in the demand reduction bids DR program, consumers initiate and send demand reduction bids to the utility. These bids consist in the available demand reduction capacity and the requested price [34].

The smart grid consumers use "Demand Response Technologies" which are by definition smart grid technologies. Those technologies include products or services that help in the active monitoring and dynamic control of electricity usage. The smart-meters are one of the most wellknown examples, these meters measure quantities and calculate costs. They can also measure in a time interval prices, among others, and send them to the consumers in order to reduce and shift usage on peak periods. Furthermore, the meters also allow new and better information to be generated and used by both the consumer and the electricity providers. This information can be presented to consumers via in home display devices, which help consumers understanding their electricity usage. Other technologies such as smart thermostats, dynamic lighting controls and dynamic energy storage systems are used as DR technologies. Thus, the deployment of the demand response can lead to higher and more sustainable levels of energy efficiency and lower toxic gas emissions $\left(\mathrm{CO}_{2}\right.$, etc. $)$.

Energy efficiency usually refers to devices or practices that provide the same level of output or benefit by using less energy. It usually focuses on reducing overall energy use, not just at certain times. The DR improves the overall efficiency of the electricity system but differs from the traditional energy efficiency by being more dynamic, meaning that it can be used to meet rising demands.

In fact, the DR programs may offer a broad range of potential benefits on system operation and energy efficiency. The participant bill savings can be considered as the main benefit of the DR program $[34,35,36]$. On the other hand, some concerns may discourage the consumers from participating in DR programs as summarized in [35]: (1) the uncertainty of the price. (2) The undefined quantity of load that might be available for reduction during an event. (3) The economic viability of participating in a DR program. (4) The willingness to maintain occupant comfort during a DR event.

The energy storage systems can be a solution that helps the DR programs to resolve the intermittency problem of renewable resources. In the next subsection we will present an overview of the energy storage systems.

\subsection{ENERGY STORAGE}

Renewable energy resources, such as solar or wind, offer a greener solution compared to traditional energy resources such as fossil fuels. However, their intermittent nature makes it difficult to balance demand and supply, which is essential in a power grid. Both electricity generation from the renewable energy resources and electricity demand are stochastic processes [37]. The Energy Storage Devices (ESD) should be a solution for random energy problem as they 
can smooth out variations in generation and demand [37]. The energy storage has long been identified as an important technology to leverage supply and demand. In an operational context, the energy storage can be used to store energy excess when supply exceeds demand and then dispatch it when it is needed which improves the energy efficiency. The energy storage can alleviate the need to generate power exactly at the time it is needed. Furthermore, it can smooth out the variations of energy utility due to random power demand and uncertain energy supply. The energy variations smoothing is desirable due to economic considerations and to the increasing incorporation of intermittent renewable resources. Intuitively, the total electricity cost can be reduced by recharging the battery from the electric power grid when the electricity price is low while discharging it during the high electricity price period [16]. Consumers may also benefit from lower-cost off-peak energy by using storage technologies in order to postpone some consumption operations to an overnight shift. There are many types of energy storage devices: mechanical, thermo-dynamic, electrochemical and electro-magnetic, each with its own characteristics. In fact, these characteristics are shown in Figure 2 and include [38]:

- ESD size that is the maximum amount of energy that can be stored in an ESD.

- Storage charging and discharging rate limit which is the limit on the charge or discharge power.

- ESD efficiency is defined by the degree of reducing each energy unit to be used later.

- Self-discharge that is the leaks of the stored energy over time.

- Depth-of-Discharge (DoD) is used to describe how deeply the battery is discharged.

- Temperature-dependency that is the temperature that can affect the charging and discharging rates and the lifetime of a battery.

- State-of-Health $(\mathrm{SoH})$ that is either expressed in terms of capacity fade or charging power fades.

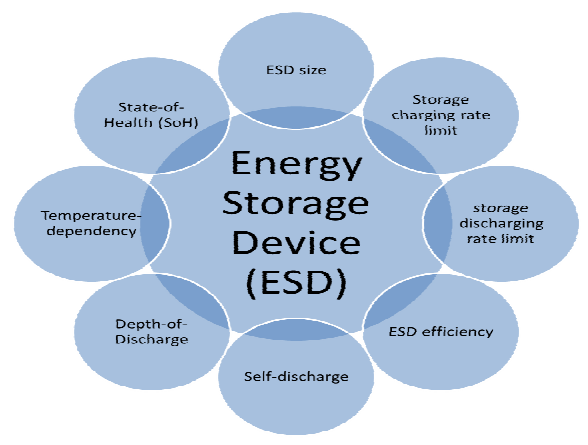

Figure 2 Storage systems characteristics

In residential areas, energy storage is practically synonymous with batteries [39]. Due to the popularity of the emerging PHEVs (Plug-in Hybrid Electric Vehicle), the battery of a PHEV may be treated as temporary electricity storage for the residential consumers [19]. Given the importance of the energy storage system, the lack of its integration is one of the drawbacks of current energy management algorithms. The development of energy management algorithms and tools can include storage to optimize the energy cost. Furthermore, other service tools for smart grid energy management such as multi-agent systems, cloud and fog computing will be shown in the following section.

\section{SERVICE TOOLS For EnERgy MANAGEMENT In SMART GRIDS}

Many service tools have an important role in the smart grid energy management (e.g. multi-agent systems, cloud computing, fog computing) and will be presented in the rest of this section. 


\subsection{The Multi-Agent Systems}

In order to explore the potential benefits of MAS in energy management, the concepts of agents and multi-agent systems need to be understood. In this context, we will discuss and define these paradigms in this section.

\subsubsection{WHAT IS AN AGENT?}

To make an intelligent decision about energy management in the smart grid, some researchers used intelligent entities called agents. Intelligent agents are a new paradigm for developing software applications. Recently, agents have been the focus of intense research in the fields of computer science and artificial intelligence. Agents are pieces of software operating on a network as a representative of a person or a device in order to perform pre-defined tasks, and allow embedding intelligent system techniques in a large distributed information system. Intelligent agents can also be utilized in the planning and operation of decentralized supply and demand. As shown in Figure 3, an agent is defined as an entity that perceives its environment through sensors and acts upon it through actuators [40].

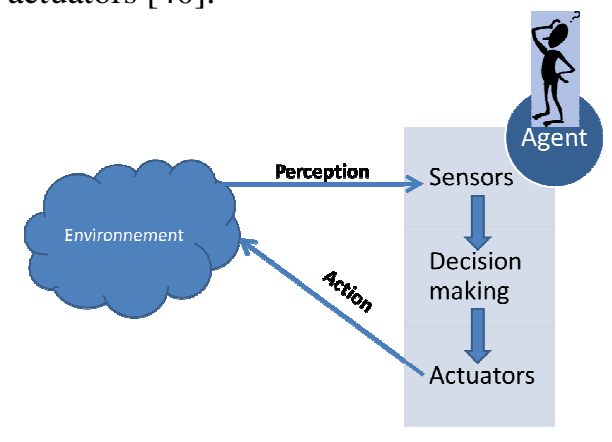

Figure 3 Basic agent behaviour

Furthermore, we can define the agent environment simply by everything external to the agent. The environment may be physical (e.g., the power system), and therefore observable through physical sensors, or it may be virtual representing the computing environment (e.g., data resources, computing resources, and other agents), observable through system calls, program invocation, and messaging [41]. A multi-agent system is a system composed of by two or more intelligent agents. In the next paragraph we will detail the multi-agent systems.

\subsubsection{WHAT IS A MAS?}

The multi-agent systems are now needed for a range of applications including diagnostics, condition monitoring, power system restoration, market simulation, network control and automation [41]. An agent cooperates with other agents to solve problems autonomously [42, 43, 44]. According to Roche et al. [45] and McArthur et al. [41], agents have three main characteristics. Firstly they are reactive so they can react to the environment rapidly. Secondly, these agents are objective-oriented so they are pro-active. Thirdly, these agents are sociable so they are able to negotiate and communicate together in their own language. Negotiation is a key issue for the multi-agent system to harmonize knowledge and resources and solve the conflicts based on a communication language. Through negotiation, agents solve some questions [46, 47, 48]. Many researchers used MAS in energy management but others believed in the effectiveness of cloud computing and fog computing for the smart grids energy management. 


\subsection{Cloud Computing And Fog Computing Architectures}

\subsubsection{ClOUd COMPUTING CONCEPT}

Cloud computing is defined as a model that presents on-demand facilities and shared resources over the Internet. Cloud computing is implemented on software resources such as stand-alone operating systems and hardware infrastructures like servers, storages and networks [49]. There are three distinct types of services in the cloud computing: (1) the Infrastructure as a Service (IaaS), (2) the Platform as a Service (PaaS) and (3) the Software as a Service (SaaS). The providers of IaaS offer physical and virtual resources such as computers, storage and virtual machines to users. Load balancing in cloud computing is performed using IaaS. PaaS is the service that develops and delivers programming models to IaaS while SaaS is responsible for helping users to run their applications without installing the software on their own computers.

Furthermore, the use of the cloud computing offers many advantages such:

- Elastic nature: cloud computing devices can change their memory capacity according to the users demand.

- Shared architecture: information can be shared between all users to reduce service costs.

- Metering architecture: metering architecture enables users to pay for their consumed resources only, thereby, it helps in cost optimization.

- Internet services: cloud computing supports the existing network infrastructure.

Figure 4 represents the cloud computing infrastructure. Moreover, the cloud computing can have three deployment models. Firstly, the private cloud is the model owned by a private organization. In this model, information is shared only within the organization. Secondly, the public cloud is owned by a service provider. Thirdly, the hybrid cloud is a composition of two clouds techniques. Figure 5 shows the hierarchical cloud computing deployment models. In fact, the cloud applications can be served from virtual energy storage and data storage devices. In addition, the components of the smart grid can communicate with the cloud and take decisions concerning energy management. Finally, the use of cloud services in smart grids energy management field avoids some problems (e.g. energy management, information management, security, etc.) encountered in this area [25]. For a more distributed system, the concept of fog computing was evolved. In the following paragraph we will explain the fog computing paradigm.

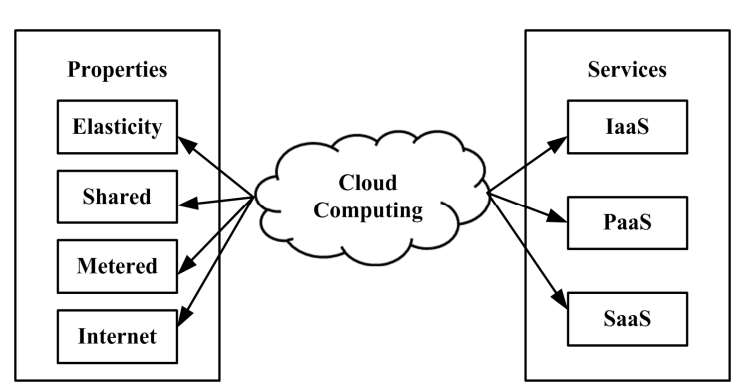

Figure 4 Cloud Computing infrastructure [25]

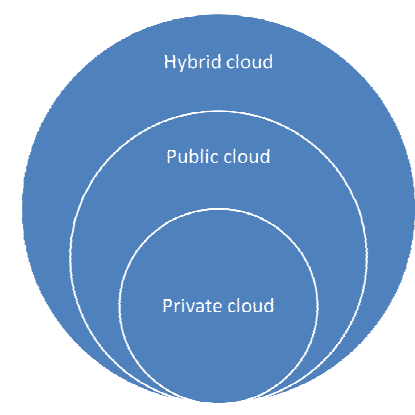

Figure 5 Cloud Computing deployment models

\subsubsection{Fog COMPUTING PARAdigm}

Fog computing is an extension of cloud computing to the edge of the network. In other words, fog computing is a cloud computing but close to the "ground" [27]. In fact, fog computing consists of 
computing, storage and networking services between end users and traditional cloud computing. Furthermore, in fog computing, the services can be hosted at the end devices such as set-topboxes or access points. By comparing it to cloud, fog computing presents a number of advantages that make it a non-trivial extension of the cloud. These advantages are as follows: the low latency, the high geographical distribution, the large number of nodes supported and the real time interaction [26]. For sake of clarity, an example of fog devices interaction is shown in Figure 6. In this example, there is a simple three levels hierarchy: (1) the cloud level, (2) the fog level and (3) the smart devices level. In this framework, each smart device is attached to one of fog servers. In addition, fog servers could be interconnected and each of them is linked to the cloud. Authors in [27] highlight the role of Fog computing in the smart grids applications. In the smart grid, energy load balancing must run on the network edge devices (smart meters and microgrids). These Fog devices automatically switch to alternative energy (solar or wind), based on demand, availability and lowest price. Figure 7 presents an example of fog computing use into the smart grid. As shown in Figure 7, fog collectors located at the edge handle the data generated by the grid sensors and devices. In addition, these collectors send control commands to the actuators. They also filter the data to be exploited locally, and send the rest to the higher tiers for visualization, real-time reports and transaction analysis. Finally, this example shows that fog supports ephemeral storage at the lowest tier to semi-permanent storage at the highest tier. After presenting some tools that can help in smart grid energy management, we will present in the following section some energy management algorithms for smart grids based on these tools.

\section{Power Management In Modern Electrical Infrastructure}

Tomorrow's consumers should negotiate and interact with their external environment. In addition, keeping the balance between demand and supply will constitute an important issue in the future electrical grid, hence the need for energy management tools. Several works studied the energy management in the smart grids or the microgrids domain but they have some drawbacks like the lack of energy storage systems, etc. A microgrid is an electrical system that incorporates renewable energy as a primary power resource, battery storage and loads. Microgrids are the optimal way to integrate renewable resources on the community level and allow for consumer participation in the electricity market [50]. Microgrids aim to improve energy production and delivery for local consumers, while facilitating a more stable electrical infrastructure with benefits towards the environmental emissions, the energy conservation, and the operational cost [15]. Furthermore, a microgrid will operate in two distinct states: interconnected with a larger utility network or islanded from it [15].

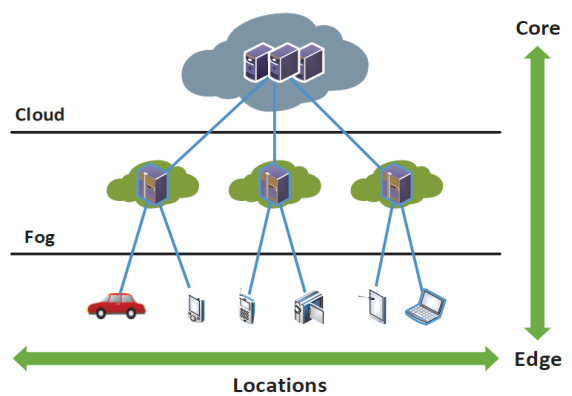

Figure 6 Example of fog computing deployment use [27]

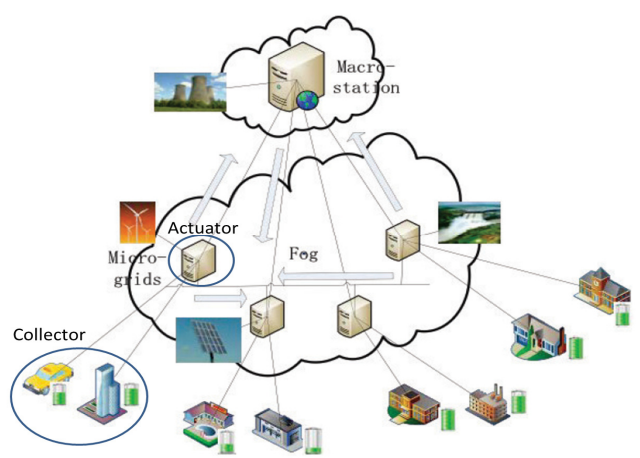

Figure 7 Fog computing example in the smart grid context [27]

In this section some energy management algorithms in the microgrids or in the smart grids will be presented. The rest of this section is organized as follows. In the subsection 4.1, we will show the 
energy prediction and the real time control use in energy management in the smart grid context. The subsection 4.2 will summarize some energy management algorithms that use the multi-agent technologies in the smart grids. In the subsection 4.3, we will explore some energy management algorithms using cloud computing paradigm. In the last subsection 4.4, we will present a qualitative comparison of all energy management algorithms shown in the previous subsections.

\subsection{Energy Prediction And Real Time Control For Power Management}

As explained previously, the penetration of the renewable energy is an increasing phenomenon and the intermittent nature of these resources creates an imbalance between production and consumption. Moreover, the use of non-scheduled renewable energy makes it difficult to balance supply and demand.

\subsubsection{Predictions ANd Energy Management}

Energy management algorithms analysis must include prediction process in order to improve the optimization results [51]. Most predictions are done over 24 time slots, each corresponding to an hour of a day. This day-ahead prediction is often adopted to predict weather conditions, load levels and market prices.

In the smart grid context where decision is based on information exchange about supply and demands, the smart grid decision makes the load and renewable energy forecasting a key component. In fact, each region has its own resource production and energy consumption based on year time and day time. Based on the previous electrical power production demands, the behavior of the load can be forecasted and estimated. Several factors influence the load in the electrical network: the weather situation (temperature, cloud coverage, etc.), the economic activity (huge modifications of load forecasting are necessary during the holiday periods), the standard working hours, etc. Classic methods of load forecasting are based on meteorological information and historic consumption data. These predicted values are used to make a more flexible system. The forecast information are exactly those used by the smart grid to improve the system efficiency $[10,52,53]$. Several researchers used the information predictions in the context of smart grid energy management. They use mathematical algorithms (integer, quadratic, dynamic and stochastic programming, game theory, evolutionary algorithms, etc.) in order to predict information [13].

Some algorithms have used storage systems in order to help in smart grid energy management $[54,55]$. Authors in [54] used a system composed of many storage agents as shown in Figure 8. In this algorithm, the authors used the predicted grid price and the predicted users demand to store the needed energy in the storage systems. Furthermore, each storage agent chooses the best moment to buy energy from the grid, which corresponds to the period when the predicted grid price is low. In addition, all consumers buy their demands from storage agents so they do not access to the grid. In this algorithm, the authors aim to minimize the energy price but in the other hand, they do not use the renewable resources and they do not consider the case when the consumer can buy the energy directly from the grid and minimize the transportation losses.

Similarly, some research efforts have focused on whole home energy consumption predictions at time frames of a day [56, 57]. A comprehensive energy management solution, however, requires a broad understanding of prediction accuracy at different entities (e.g. appliance and home) as well as different time horizons (hour, day, or week). A broad understanding of predictability may be used to inform the design of energy management solutions by allowing a designer to tune the 
system to tolerate prediction error, or to make smart decisions about integrating or excluding appliances known to have unpredictable usage patterns.

Another optimization load control scheme based on Linear Programming (LP) was proposed in [58]. The main goal of this research is to minimize the households' bill. To realize this goal, the authors proposed an optimization-based residential load control scheme that uses real time pricing market (RTP). A price predictor unit estimates the future prediction prices by using weighted averaging filter to past prices. This scheme combines the prediction of price and consumption in order to schedule demands and make an optimal decision.

Subramanian et al. [59] proposed a day-ahead price-optimization algorithm for electrical utilities in the smart grid framework. This research has the ability to predict the day-ahead pricing plans in order to manage residential electricity loads. This study uses historical data from the real-world resources to calibrate the underlying model and to measure the quality of the model fit. The proposed algorithm reduces costs by optimally shifting peak loads to off-peak periods, thereby reducing the need for spot-market electricity usage. The research in [60] proposed predictive control model of energy management in the smart grid to control and minimize the cost function. A scheduling of battery usage is determined based on many parameters. These parameters can be defined as variable cost values, power consumption and generation profiles, as well as functional constraints under uncertainty due to variations in the power generator model. This algorithm does not use a storage system.

In order to reduce the intermittency of photovoltaic resources, Kanchev et al. [14] developed an energy management algorithm based on predicted data. The authors used two storage technologies at the consumer level to enable grid demand management and renewable energy integration. Batteries are the first storage technologies. They are used to ensure an energy reserve for the grid operator. In addition, supercapacitors are considered as the second storage technologies in this algorithm and are used to balance fast power variations coming from the photovoltaic generator and from the primary frequency control. A strategy has been presented to drive storage systems according to the solar energy resources and grid requirements. In this proposed strategy, a deterministic operational power planning has been proposed to perform the day-ahead power scheduling for the conventional and photovoltaic generators. The presented scheme relies on photovoltaic power predictions and load forecasting. The scheme also sets out plans for the use of the distributed battery storage.

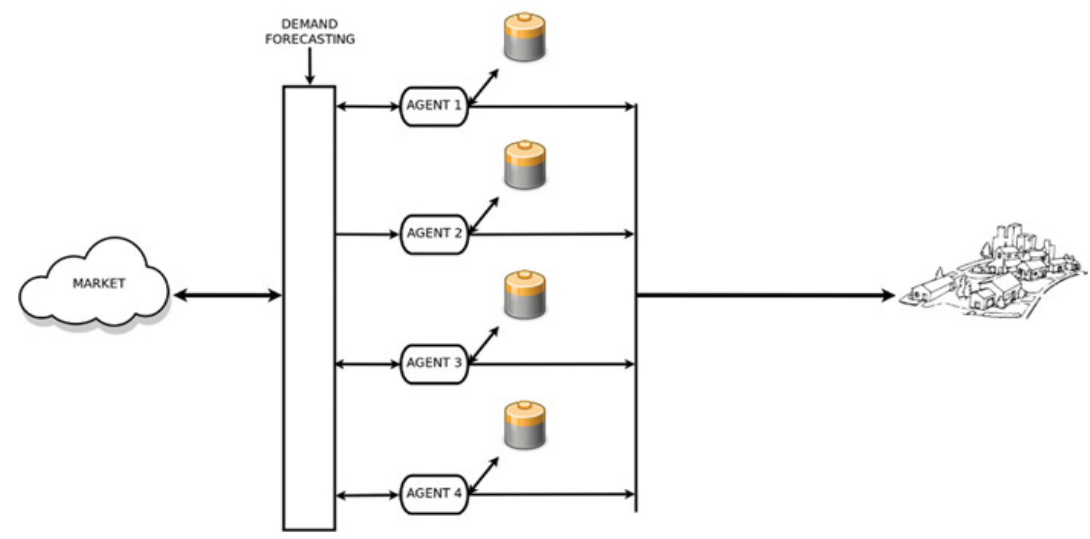

Figure 8 The storage agent architecture by Alberola et al. [54] 
In the researches done in $[14,58,59,60]$, the developed algorithm does not adjust the predicted values when a perturbation occurs (i.e. new consumer in the network, the failure of a production unit, etc.).

Unlike previous researches, Rose et al. [53] developed a new scoring rule mechanism called Sum of Others' plus Max (SOM). This new scheme contains a centralized agent that aggregates all predicted information. Based on aggregated information, the centralized agent buys all needed energy to the system. In order to encourage agents to report their true demands to the center, this last rewards agents from a budget that is equal to the savings made by using the agents' information. By using the proposed algorithm (SOM), the center distributes the savings to the agents in a budget-balanced way. As the algorithm is centralized, this may calls into question the scalability of the algorithm and constitutes bottlenecks.

Instead of centralization used in [53], Wang et al. [52] used a distributed system in order to control the energy storage systems based on predicted photovoltaics output. The authors argued that the prediction of the power generation and load power consumption is very important to develop a storage control algorithm for a better energy management in the context of households. This algorithm adjusts at each time slot all the prediction values when a disturbance occurs and the predicted value does not match the real value. Based on predicted values, the authors developed an algorithm that helps to plan the future charging and discharging schemes for storage systems in the next periods and chooses the best way to charge the battery. However, this algorithm does not use intelligent interactions between consumers in order to reduce bill.

Similary, Cecati et al. [61] proposed an energy management algorithm that reduces the energy cost for consumers and resolves the problem of renewable resources intermittency in the smart grid context. The proposed algorithm uses the generation and load forecasts to determine the optimum way to purchase energy. Firstly, the energy management system schedules a one dayahead predicted values. Secondly, a real time intra-day optimization operation is proposed. This real time optimization can modify the predicted values in order to consider the operation requirements. To resolve the problem of the high data integration into the existing energy management systems, the authors use a learning architecture based on fully connected neural networks. In this way, they can lower the computational time needed to predict the optimal schedule of generation. Moreover, they can allow benefits such as short processing time, required by real-time operation, and a simple implementation. However, this algorithm does not use the intelligent interaction between consumers in order to reduce bill.

\subsubsection{Real Time Control Strategy For EnERgy Management}

Generally, some perturbations may occur on the system causing a dispatch between the predicted values and the real ones. Real time energy management is a procedure used in the smart grid or in the microgrid to manage the grid usage, the storage and the production in order to satisfy all energy demands with a minimum cost. During real-time operations, the generation and the load must be matched.

An algorithm based on the predictions and the real-time energy management is proposed by Hooshmand et al. [62]. This research work uses the energy predictions and the real-time energy management in order to relax the issue of sudden unforecasted unbalances between supply and demand. The energy storage systems are used in this algorithm in order to minimize the costs. The proposed system consists of the four following nodes' types: (1) the demand node $\mathrm{D}(\mathrm{t})$ that is the node energy consumption. (2) The node of renewable energy which is made up of wind energy, solar energy, etc. (3) The grid node that is able to buy exceeded energy from producers or to sell the needed energy to end users. (4) The storage node stores unused renewable energy or 
imports energy with low prices from the grid. In this research, the authors use the forecasted load profile and renewable energy generation to minimize the cost of energy. In this context, they proposed a novel Model Predictive Control (MPC) which is by definition a control system. It will be responsible for energy management using current and future information of the load profiles of renewable energy, battery state of charge SOC, etc. MPC can be defined as a class of control policies which uses a model that projects the behavior of the system under control. The proposed MPC corrects any prediction error, solves the optimization problem, minimizes real-time generation of energy and optimizes energies costs. However, this research does not take into consideration the sudden uses of the energy (e.g new user in the system). In order to reduce severe environment impacts, Sechilariu et al. [63] proposed an energy management algorithm in the smart grid. In their research, the authors focus on building-integrated microgrid design and applied an energy storage and smart grid communication. The researchers use a photovoltaic resource in order to reduce toxic gas emissions. The main goal of this work is to balance the supply and the demand in a real-time. In this context, a power balancing strategy using smart grid interactions was proposed. The proposed strategy reduces grid peak consumption, avoids undesirable grid power injection and makes full use of local photovoltaic production. However, in this research the authors do not use predictions in order to minimize users' bill.

The research in [16] focuses on a study to minimize the expected electricity cost with real-time electricity pricing. This research proposes an algorithm that uses energy storage to harvest excessive renewable energy generation for later use. In addition, the energy storage charges the battery when the electricity price is low while discharging it when the electricity price is high. The authors increase battery capacity by using optimization techniques. This research focuses on elastic energy demands (computers, televisions, etc.) and proposed to queue those demands and serve them with a delay to guarantee the finite worst case delay for any buffered energy demand. However, this algorithm does not use energy predictions in order to optimize bill.

An important number of energy management algorithms use a multi-agent system for smarter solutions, we will define some of those algorithms in the next paragraphs.

\subsection{Energy Management Using Multi-Agent Systems}

Several researchers adopted multi-agent systems for energy management in the smart grids or the microgrids. Roche et al. [64] proposed an energy management algorithm in the smart grids that uses the MAS. In this scheme, the authors used a multi-agent system shown in Figure 9.

The proposed multi-agent architecture consists of several agents, divided into three categories:

- Control Agents: they include physical components like turbines and storage. A turbine agent is created for each turbine in the microarray and resides in the turbine control system. It communicates with the SCADA agent, sends its current state through its actions, and receives instructions in return.

- Management System Agents: SCADA, dispatching and planning. The SCADA agent plays the role of a supervisor and business controller. Based on the data received from the SCADA agent, the dispatch agent calculates the optimum operating point for each of the micro-network agents. It also maintains a database containing the needed information to determine the correct distribution of powers by using economic and environmental data. The planning agent is responsible for planning in advance, if possible optimal and operation of the set, with production forecasts, demand and prices issued by agents.

- Auxiliary staff: it includes prediction agent that predicts users' data and production. 


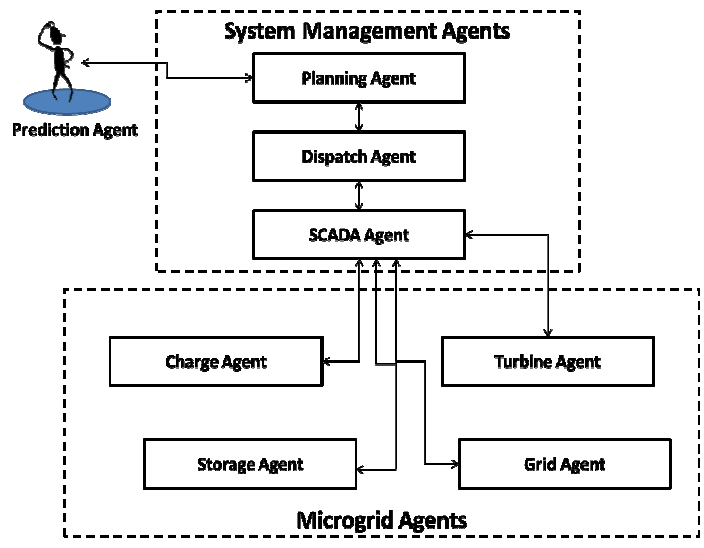

Figure 9 Illustration of Roche et al. system agents

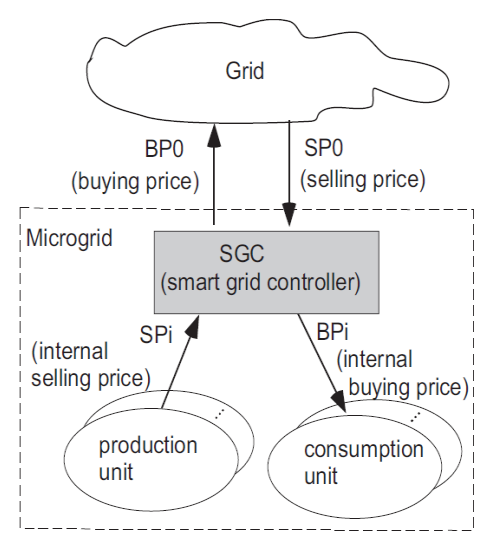

Figure 40 The system components by Nagata et al. algorithm [42]

The authors in [64] ensure the energy efficiency but they do not negotiate the energy purchase to optimize the consumers' bill. An energy management algorithm for the smart grids was proposed by Logenthiran et al. [65]. The objective of this research is to develop and simulate a multi-agent system that enables an electricity market for the operation of a microgrid in both islanded and grid-connected modes. In this research, the microgrid maximizes its profit by optimizing the power exchange with the main grid. During the islanded mode operation, the microgrid satisfies the local energy demand using its local power production and minimizes load losses. During gridconnected mode, the microgrid sells power to internal load of the microgrid and also exchanges power with the main grid at market price. When the amount of power produced by microgrid resources is not enough, or too expensive to cover the local load, power is bought from the upstream network and sold to the consumers at the same price. The multi-agent system in this algorithm is used in order to plan in real-time the produced energy and the storage system use. However, this algorithm does not allow negotiating the energy purchase to minimize the consumers' bills.

Unlike the proposal described in [65], an algorithm for energy management in smart grid using a mutli-agent system and a negotiation algorithm was proposed by Nagata et al. [42]. The authors proposed this algorithm in order to reduce the energy costs. The proposed system components are shown in Figure 10. The selling price (SP0) and the buying price (BP0) are two parameters announced by the grid operator. The smart grid controller unit (SGC) in this system aims to negotiate and optimize the buying prices for consumers. Moreover, production units and consumption units belong to the smart grid. These units adjust their set point (SPi and BPi) after negotiation with other units based on the grid price, their operational costs, and the load demand. The system is constructed with six types of agents:

1. The Grid Agent (GridAG): it has two principal roles: buying kWh from the smart grid or selling $\mathrm{kWh}$ to it.

2. The Generator Agent (GAG): its role is to maximize the total benefit.

3. The Seller Agent (SAG): created by the generator agent to sell $\mathrm{kWh}$ to the market.

4. The Load Agent (LAG): its role is to create several buyer agents.

5. The Buyer Agent (BAG): its role is to buy $\mathrm{kWh}$ from the market.

6. The smart grid Control Agent (SGC): its role is to optimize the smart grid operation by using a negotiation algorithm. 
It is worth noting that, in this algorithm, each SAG and BAG is assigned to a specific amount of power. The centralization and the lack of storage systems can be considered as disadvantages of this research.

Colson et al. [15] proposed an energy management algorithm for microgrid, using a multi-agent system. The authors integrate three basic agent types: the producer agent, the consumer agent and the observer agent. The responsibilities of the producer agent can be defined as:

- Monitoring power.

- Determining the cost of the power supplied by the component.

- Providing information to other agents.

The consumer agent is responsible for:

- Monitoring the amount of consumed power.

- Determining the amount of the instantaneous active and reactive power.

- Negotiating the purchase of energy.

While responsibilities of the observer agent are:

- Monitoring specific parameters within the network of micro-network.

- Providing information to other agents regarding the state of the node.

In this algorithm, consumer agents use negotiation to get the energy at the lowest price. The lack of the energy storage system integration is the drawback of this algorithm.

Similarly, an agent-based algorithm was proposed in [66]. In this work, the authors proposed an agent-based algorithm allowing more efficient use of energy while minimizing cost and taking into account the integration of distributed renewable energy resources. This proposed system is composed of three types of agents:

1. Generator Company agents $(\mathrm{GC})$ : they represent the big generator companies that are the main resources of energy.

2. Prosumer agents: they represent small resources of renewable energy distributed near the consumers. They obviously produce and consume energy. They produce a smaller quantity of electricity than GC.

3. Consumer agents: the regular consumer agent is an agent that cannot produce energy. It is only a purchaser of energy.

In this proposal, prosumers prefer to sell the unused quantity of energy. Furthermore, the consumers act to determine and negotiate the purchase of energy in order to reduce their bill. The goal of each consumer agent is to maximize its profit in terms of unit price paid per day. Each consumer divides its data into three priorities. Firstly, the vital loads are satisfied. The consumer negotiates the cost and chooses the resource that minimizes its own cost of purchase. In this proposal, the demands of consumers are first met with supply from renewable resources. If the renewable resources cannot meet the total energy requirements of all consumers, then the traditional resources are used to meet these demands. In this algorithm, the authors do not use the energy storage systems that would improve outcomes and reduce the consumers' bill.

Similarly, Vytelingum et al. [67] argued that using micro-storage devices at home to save power via the Smart Grid is reducing the burning of fossil fuels. In this research, all residential consumers are modeled as autonomous agents (SmartHome), responsible for shifting their consumption in order to maximize the residential revenue in addition to several social welfare factors. They proposed an agent-based micro-storage management technique with a provided general framework within which to analyze the Nash equilibrium of an electricity grid and devise 
new agent-based storage learning strategies that adapt to the market conditions. However, this research does not take into consideration users' comfort.

Ramchurn et al. [68] proposed a MAS-based control mechanism to incorporate consumer preferences in managing demand. All agents, in this algorithm, represent consumers and can communicate with the grid and optimize energy consumption. This algorithm helps in controlling a system containing green energy suppliers operating within the grid and a number of individual homes. This approach reduces consumers' energy bill, but does not take into consideration users' comfort.

The authors in the research described in $[69,70]$ proposed a novel energy management algorithm for the smart grids using multi-agent systems, intelligent storage systems, and a negotiation algorithm. In this work, the authors integrate the storage systems in order to minimize the access to the grid and the consumers' bills. The main goal of the research developed in [70] is to use renewable resources (i.e. wind) and resolve the problem of their intermittency. In addition, in [70], the authors aim to optimize the consumer bill so they adopted a negotiation algorithm to choose the combination of consumers and producers that minimizes the energy bill. In this research, the authors proposed a multi-agent system composed of four types of agents shown in Figure 11:

1. The grid agent, introduced in the smart grid, which role is to satisfy the energy lack and buy the exceeded energy production.

2. The storage agent, introduced in a centralized battery, aims to control the energy storage.

3. The prosumer agent, introduced in renewable resources, controls the distribution of the energy it produces.

4. The consumer agent, introduced in smart homes, negotiates the energy purchase with other consumers and prosumers.

In this algorithm, the consumers negotiate the energy purchase from all resources (producers, grid and storage system). Each consumer is selfish and chooses the combination that minimizes its own bill and sends its proposal to the other consumers in its network. Finally, the consumers choose the proposal that has the maximal utility function (i.e. the minimal cost). In this research, the authors minimize consumers' bill and use optimally all renewable energy production. The next section highlights cloud computing use in the smart grids energy management.

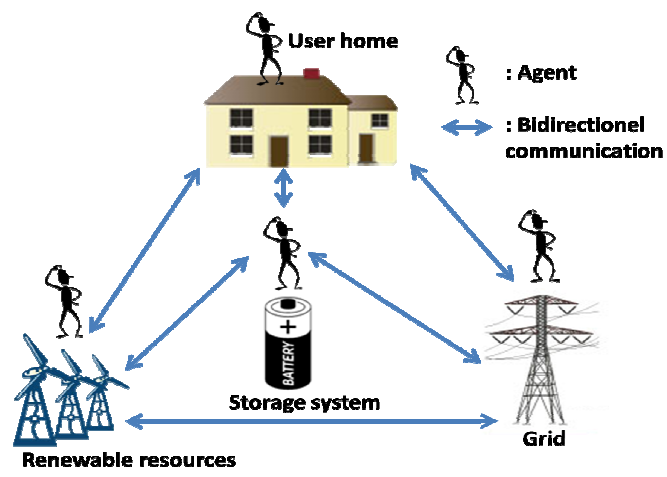

Figure 51 Illustration of the proposed system of the researches presented in $[69,70]$

\subsection{Energy Management Using Cloud Computing Architecture}

Many authors used the cloud computing in the smart grid energy management. In this section we will present some of the proposed algorithms. 
Ghamkhari et al. [71] presented an optimization-based strategy for data centers. The authors developed a mathematical model that aims to minimize the data center's energy.

The authors in [72] proposed a Building Energy Management algorithm called BEMS using smart grids and cloud computing. The aim of this work is to design a management model by using the cloud concept. The authors implement their algorithm in a building. In addition, the proposed system consists of three components: the Power Monitoring Entity that aims to monitor and control device's power consumption, the Environmental Information Entity that aims to collect environmental information, and the System Manager that collects an manages data and provides services to users. Furthermore, the authors used a cloud computing three-layered architecture. Firstly, the service layer is composed of a service priority manager that is responsible for the priority management of services. In addition, this layer allocates the resources to the high priority demand. Furthermore, the service analyzer layer analyzes the requested service and determines the required resources. Finally, the service profile database stores the information from services already requested to response quickly without data analysis. Secondly, the management layer is responsible for allocating resources, gathering data and categorizing the situational events for database storage and managing the power and environmental information. Thirdly, the physical layer aims to manage heterogeneous devices such as mobile phones, laptops, etc.

Table 1. Review of energy management algorithms characteristics

\begin{tabular}{|c|c|c|c|c|c|c|}
\hline Algorithm & $\begin{array}{l}\text { Use } \\
\text { MAS }\end{array}$ & $\begin{array}{l}\text { Use } \\
\text { Storage } \\
\text { device }\end{array}$ & $\begin{array}{l}\text { Centralisa } \\
\text { tion }\end{array}$ & $\begin{array}{l}\text { Use } \\
\text { predicted } \\
\text { data }\end{array}$ & $\begin{array}{l}\text { Update } \\
\text { predicted } \\
\text { data }\end{array}$ & $\begin{array}{l}\text { Use } \\
\text { negotiati } \\
\text { on }\end{array}$ \\
\hline Alberola et al. [54] & $\checkmark$ & $\checkmark$ & $\mathrm{X}$ & $\checkmark$ & $\mathrm{X}$ & $\mathrm{X}$ \\
\hline $\begin{array}{l}\text { Mohsenian et al. } \\
\text { [58] }\end{array}$ & $\mathrm{X}$ & $\checkmark$ & $\bar{X}$ & $\checkmark$ & $\mathrm{X}$ & $\mathrm{X}$ \\
\hline $\begin{array}{l}\text { Subramanian et al. } \\
\text { [59] }\end{array}$ & $\mathrm{X}$ & $\mathrm{X}$ & $\mathrm{X}$ & $\checkmark$ & $\mathrm{X}$ & $\mathrm{X}$ \\
\hline Prodan et al. [60] & $\mathrm{X}$ & $\checkmark$ & $\mathrm{X}$ & $\checkmark$ & $\mathrm{X}$ & $\mathrm{X}$ \\
\hline Kanchev et al. [14] & $\mathrm{X}$ & $\checkmark$ & $\mathrm{X}$ & $\checkmark$ & $\mathrm{X}$ & $\mathrm{X}$ \\
\hline Rose et al. [53] & $\checkmark$ & $\checkmark$ & $\checkmark$ & $\checkmark$ & $\mathrm{X}$ & $\mathrm{X}$ \\
\hline Wang et al. [52] & $\mathrm{X}$ & $\checkmark$ & $\mathrm{X}$ & $\checkmark$ & $\checkmark$ & $\mathrm{X}$ \\
\hline Cecati et al. [61] & $\mathrm{X}$ & $\mathrm{X}$ & $\mathrm{X}$ & $\checkmark$ & $\mathrm{X}$ & $\mathrm{X}$ \\
\hline $\begin{array}{l}\text { Hooshmand et al. } \\
\text { [62] }\end{array}$ & $\mathrm{X}$ & $\checkmark$ & $\mathrm{X}$ & $\checkmark$ & $\checkmark$ & $\mathrm{X}$ \\
\hline $\begin{array}{l}\text { Sechilariu et al. } \\
\text { [63] }\end{array}$ & $\mathrm{X}$ & $\checkmark$ & $\mathrm{X}$ & $\mathrm{X}$ & $\mathrm{X}$ & $\mathrm{X}$ \\
\hline Guo et al. [16] & $\mathrm{X}$ & $\checkmark$ & $\mathrm{X}$ & $\checkmark$ & $\mathrm{X}$ & $\mathrm{X}$ \\
\hline Roche et al. [64] & $\checkmark$ & $\checkmark$ & $\mathrm{X}$ & $\checkmark$ & $\mathrm{X}$ & $\mathrm{X}$ \\
\hline $\begin{array}{l}\text { Logenthiran et al. } \\
\text { [65] }\end{array}$ & $\checkmark$ & $\checkmark$ & $\mathrm{X}$ & $\mathrm{X}$ & $\mathrm{X}$ & $\mathrm{X}$ \\
\hline Nagata et al. [42] & $\checkmark$ & $\mathrm{X}$ & $\checkmark$ & $\checkmark$ & $\mathrm{X}$ & $\checkmark$ \\
\hline Colson et al. [15] & $\checkmark$ & $\mathrm{X}$ & $\mathrm{X}$ & $X$ & $\mathrm{X}$ & $\checkmark$ \\
\hline Nabouch et al. [66] & $\checkmark$ & $\mathrm{X}$ & $\mathrm{X}$ & $X$ & $\mathrm{X}$ & $\checkmark$ \\
\hline Klaimi et al. [70] & $\checkmark$ & $\checkmark$ & $\checkmark$ & $\checkmark$ & $\mathrm{X}$ & $\checkmark$ \\
\hline Ngoc et al. $[56,57]$ & $\checkmark$ & $\mathrm{X}$ & $\mathrm{X}$ & $\checkmark$ & $\mathrm{X}$ & $X$ \\
\hline $\begin{array}{l}\text { Vytelingum et al. } \\
\text { [55] }\end{array}$ & $\checkmark$ & $\checkmark$ & $\mathrm{X}$ & $\checkmark$ & $\mathrm{X}$ & $\mathrm{X}$ \\
\hline $\begin{array}{l}\text { Ramchurn et al. } \\
\text { [68] }\end{array}$ & $\checkmark$ & $\checkmark$ & $\mathrm{X}$ & $\checkmark$ & $\mathrm{X}$ & $\mathrm{X}$ \\
\hline
\end{tabular}


International Journal of Artificial Intelligence and Applications (IJAIA), Vol. 7, No. 4, July 2016

\subsection{RevieW OF The Different Algorithms}

Quantitative analysis of the summarized algorithms is presented in this section. The centralization is the drawback of the algorithm presented in [53]. The research presented in [61] has a lack in storage systems use. The algorithm in [62] solves the optimization problem, minimizes real-time generation of energy and optimizes energies costs. Moreover, this research does not take into consideration the sudden energy use. Furthermore, the algorithm described in [65] is used in order to plan in real-time the produced energy and the storage system use. However, this algorithm does not negotiate the energy purchase to minimize the consumers' bills. Moreover, the research of Nagata et al. [42] optimizes consumers' bills but the centralization and the lack of storage systems can be considered as disadvantages of this research. In addition, Colson et al. [15] presents an algorithm that uses negotiation to get the energy at the lowest price. This algorithm has a drawback which is lack of the integration of storage system. Nabouch et al. [66] have not integrated storage systems that may improve outcomes and reduce the consumers' bills.

The Table 1 presents a review of all summarized energy management algorithms presented in this paper.

\section{CONCLUSION}

The integration of the smart grids technologies will be an extremely important task in the near future. The main target is to develop general and exceptionally flexible integration strategies for the use of distributed energy resources and/or storage systems. Therefore, there is an evident need to investigate the feasibility/efficiency of integrating different distributed energy storage systems in combination with distributed energy resources and their influence on the penetration of renewable energy. Moreover, it is clearly important to develop standardized control strategies for energy management in the smart grid systems including the storage and renewable production side.

In this work we have presented the need for energy management for efficient usage of electricity in the smart grid. We presented the current electricity grids that absolutely must adapt to become more intelligent, that is to say, integrate new information technologies and communication. ICTs permit interactions among the computational and the physical elements of the smart grid. Furthermore, ICTs will meet the challenges of integrating renewable power production by providing energy management algorithms.

The massive integration of renewable energy resources in electricity networks is an issue that aims to be solved. The main goal to reach is the management of the intermittent power into the power grids. Finally, we presented also several algorithms of energy management using the storage and/or multi-agent systems and many algorithms that use the cloud computing architecture. This presentation has been concluded by a brief qualitative discussion of these proposals.

\section{ACKNOWLEDGEMENTS}

This work is supported by grants from the Troyes University of Technology and the Lebanese University and is partly supported by the Champagne-Ardenne region research project SOLOTEC and the Lebanese-French research project CEDRE Number 32928XK. 
International Journal of Artificial Intelligence and Applications (IJAIA), Vol. 7, No. 4, July 2016

\section{REFERENCES}

[1] V.C. Gungor et al. Smart grid technologies: Communication technologies and standards. Industrial Informatics, IEEE Transactions on, 529-539, Nov 2011.

[2] C. Gao et al. A review of voltage control in smart grid and smart metering technologies on distribution networks. In Universities' Power Engineering Conference (UPEC), Proceedings of 2011 46th International, pages 1-5, Sept 2011.

[3] J.O. Petinrin et al. Smart power grid: Technologies and applications. In Power and Energy (PECon), 2012 IEEE International Conference on, pages 892-897, Dec 2012.

[4] J. Ou, et al. Mapping global fossil fuel combustion co2 emissions at high resolution by integrating nightlight, population density, and traffic network data. IEEE Journal of Selected Topics in Applied Earth Observations and Remote Sensing, 1674-1684, 2016.

[5] R. Atia et al. Sizing and analysis of renewable energy and battery systems in residential microgrids. IEEE Transactions on Smart Grid, 1-10, 2016.

[6] S. Gottwalt et al. Modeling and valuation of residential demand exibility for renewable energy integration. IEEE Transactions on Smart Grid, PP(99):1-10, 2016.

[7] H. Chen et al. Key technologies for integration of multitype renewable energy sources 2014;research on multi-timeframe robust schedulingdispatch. IEEE Transactions on Smart Grid, 471-480, 2016.

[8] Y. Yan et al. A survey on smart grid communication infrastructures: Motivations, requirements and challenges. IEEE Communications Surveys Tutorials, 5-20, 2013.

[9] Y. Feng et al. Energy efficient self-sustaining wireless neighborhood area network design for smart grid. Smart Grid, IEEE Transactions on, 220-229, Jan 2015.

[10] C.W. Potter et al. Building a smarter smart grid through better renewable energy information. In Power Systems Conference and Exposition, 2009. PSCE '09. IEEE/PES, pages 1-5, March 2009.

[11] N. Matta et al. Pribacc: In-network sensor data processing for efficient smart grid monitoring applications. In Global Information Infrastructure Symposium, 2013, pages 1-6, Oct 2013.

[12] N. Matta et al. A wireless sensor network for substation monitoring and control in the smart grid. In Green Computing and Communications (GreenCom), 2012 IEEE International Conference on, pages 203-209, Nov 2012.

[13] K. Mets et al. Distributed multi-agent algorithm for residential energy management in smart grids. In Network Operations and Management Symposium (NOMS), 2012 IEEE, pages 435-443, April 2012.

[14] H. Kanchev et al. Energy management and operational planning of a microgrid with a pv-based active generator for smart grid applications. Industrial Electronics, IEEE Transactions on, 4583-4592, Oct 2011.

[15] C.M. Colson et al. Algorithms for distributed decision-making for multi-agent microgrid power management. In Power and Energy Society General Meeting, 2011 IEEE, pages 1-8, July 2011.

[16] G. Yuanxiong et al. Optimal power management of residential customers in the smart grid. Parallel and Distributed Systems, IEEE Transactions on, 23(9):1593-1606, Sept 2012.

[17] N. Javaid et al. A survey of home energy management systems in future smart grid communications. In Broadband and Wireless Computing, Communication and Applications (BWCCA), 2013 Eighth International Conference on, pages 459-464, Oct 2013.

[18] L. Yang et al. Cost-effective and privacy-preserving energy management for smart meters. IEEE Transactions on Smart Grid, 6(1):486-495, 2015.

[19] W. Zhang et al. Distributed online optimal energy management or smart grids. IEEE Transactions on Industrial Informatics, 717-727, 2015.

[20] R. Belkacemi et al. Experimental implementation of multi-agent system algorithm for distributed restoration of a smart grid system. In SOUTHEASTCON 2014, IEEE, pages 1-4, March 2014.

[21] A. Sardouk et al. Agent strategy data gathering for long life wsn. International Journal of Computer Networks \& Communications, 71-90, 2010.

[22] C. M. Elliott.Distributed multi-agent systems-a literature survey and inquisitive discussion. In 2014 IEEE Aerospace Conference, pages 1-7, 2014.

[23] B. Bitzer et al. Cloud computing framework for smart grid applications. In Power Engineering Conference (UPEC), 2013 48th International Universities', pages 1-5, Sept 2013.

[24] A.-H. Mohsenian-Rad et al. Coordination of cloud computing and smart power grids. In Smart Grid Communications (SmartGridComm), 2010 First IEEE International Conference on, pages 368-372, Oct 2010 . 
[25] S. Bera et al. Cloud computing applications for smart grid: A survey. Parallel and Distributed Systems, IEEE Transactions on, PP(99):1-1, 2014.

[26] F. Bonomi et al. Fog computing and its role in the internet of things. In Proceedings of the First Edition of the MCC Workshop on Mobile Cloud Computing, MCC '12, pages 13-16, 2012.

[27] I. Stojmenovic et al. The fog computing paradigm: Scenarios and security issues. In Computer Science and Information Systems (FedCSIS), 2014 Federated Conference on, pages 1-8, Sept 2014.

[28] K. Hong et al. Mobile fog: A programming model for large-scale applications on the internet of things. In Proceedings of the Second ACM SIGCOMM Workshop on Mobile Cloud Computing, MCC '13, pages 15-20, 2013.

[29] S. Sofana et al. A smart survey on demand response potential in global energy market. Indian Journal of Science and Technology, 2015.

[30] Y. W. Law et al. Demand response architectures and load management algorithms for energy efficient power grids: A survey. In Knowledge, Information and Creativity Support Systems (KICSS), 2012 Seventh International Conference on, pages 134-141, 2012.

[31] J. S. Vardakas et al. A survey on demand response programs in smart grids: Pricing methods and optimization algorithms. IEEE Communications Surveys Tutorials, 152-178, 2015.

[32] R. Deng et al. A survey on demand response in smart grids: Mathematical models and approaches. IEEE Transactions on Industrial Informatics, 570-582, 2015.

[33] P. Faria et al. Demand response programs definition using demand price elasticity to define consumers aggregation for an improved remuneration structure. In Innovative Smart Grid Technologies Europe (ISGT EUROPE), 2013 4th IEEE/PES, pages 1-5, Oct 2013.

[34] S. Pierluigi. Demand response and smart grids--a survey. Renewable and Sustainable Energy Reviews, 461 - 478, 2014.

[35] M.C. Falvo et al. Electric vehicles integration in demand response programs. In Power Electronics, Electrical Drives, Automation and Motion (SPEEDAM), 2014 International Symposium on, pages 548-553, June 2014.

[36] M.H. Albadi et al. A summary of demand response in electricity markets. Electric Power Systems Research, 1989 - 1996, 2008.

[37] Y. Ghiassi-Farrokhfal et al. Toward a realistic performance analysis of storage systems in smart grids. Smart Grid, IEEE Transactions on, 402-410, Jan 2015.

[38] A. A. Jamali et al. Energy storage systems and their sizing techniques in power system-a review. In 2015 IEEE Conference on Energy Conversion (CENCON), pages 215-220, Oct 2015.

[39] A. Kawashima et al. Energy management systems based on real data and devices for apartment buildings. In Industrial Electronics Society, IECON 2015 - 41st Annual Conference of the IEEE, pages 3212-3217, 2015.

[40] M.H. Cintuglu et al. Real-time implementation of multiagent-based game theory reverse auction model for microgrid market operation. Smart Grid, IEEE Transactions on, 1064-1072, March 2015.

[41] S.D.J. McArthur et al. Multi-agent systems for power engineering applications part i: Concepts, approaches, and technical challenges. Power Systems, IEEE Transactions on, 1743-1752, Nov 2007.

[42] T. Nagata et al. A multi-agent approach to smart grid energy management. In IPEC, 2012 Conference on Power Energy, pages 327-331, Dec 2012.

[43] G.H. Merabet et al. Applications of multi-agent systems in smart grids: A survey. In Multimedia Computing and Systems (ICMCS), 2014 International Conference on, pages 1088-1094, April 2014.

[44] A. Sharma et al. A multi-agent-based power system hybrid dynamic state estimator. Intelligent Systems, IEEE, 52-59, May 2015.

[45] R. Roche et al. Multi-agent systems for grid energy management: A short review. In IECON 201036th Annual Conference on IEEE Industrial Electronics Society, 3341-3346, Nov 2010.

[46] T. Hai-Jun et al. An extended contract-net negotiation model based on task coalition and genetic algorithm. In Machine Learning and Cybernetics, 2007 International conference on, volume 2, pages 879-884, Aug 2007.

[47] X. Dong et al. Multi-attribute negotiation model based on internal factors argumentation. In Management Science and Engineering (ICMSE), 2013 International Conference on, pages 20-27, July 2013.

[48] G. Rohbogner et al. What the term agent stands for in the smart grid definition of agents and multiagent systems from an engineer's perspective. In Computer Science and Information Systems (FedCSIS), 2012 Federated Conference on, pages 1301-1305, Sept 2012. 
[49] C. Sivapragash et al. Advanced cloud computing in smart power grid. In Sustainable Energy and Intelligent Systems (SEISCON 2012), IET Chennai 3rd International on, pages 1-6, Dec 2012.

[50] P. Toma et al. Sizing photovoltaic-wind smart microgrid with battery storage and grid connection. In Automation, Quality and Testing, Robotics, 2014 IEEE International Conference on, pages 1-5, May 2014.

[51] Chen Changsong et al. Energy trading model for optimal microgrid scheduling based on genetic algorithm. In Power Electronics and Motion Control Conference, 2009. IPEMC '09. IEEE 6th International, pages 2136-2139, 2009.

[52] W. Yanzhi et al. Adaptive control for energy storage systems in households with photovoltaic modules. Smart Grid, IEEE Transactions on, 5(2):992-1001, March 2014.

[53] H. Rose et al. A scoring rule-based mechanism for aggregate demand prediction in the smart grid. In Proceedings of the 11th International Conference on Autonomous Agents and Multiagent Systems Volume 2, AAMAS '12, pages 661-668, 2012.

[54] J. M. Alberola et al. A self-configurable agent-based system for intelligent storage in smart grid. volume 365 of Communications in Computer and Information Science, pages 240-250. 2013.

[55] P. Vytelingum et al. Theoretical and practical foundations of large-scale agent-based micro-storage in the smart grid. J. Artif. Int. Res., 765-813, 2011.

[56] Ngoc Cuong Truong et al. Towards appliance usage prediction for home energy management. In Proceedings of the Fourth International conference on Future Energy Systems, e-Energy '13, pages 287-288, 2013.

[57] Ngoc Cuong et al. Forecasting multi-appliance usage for smart home energy management. In 23rd International Joint Conference on Artificial Intelligence (IJCAI 2013), April 2013.

[58] A.-H. Mohsenian-Rad et al. Optimal residential load control with price prediction in real-time electricity pricing environments. Smart Grid, IEEE Transactions on, 120-133, Sept 2010.

[59] S. Subramanian et al. Dynamic price optimization models for managing time-of-day electricity usage. In Smart Grid Communications (SmartGridComm), 2013 IEEE International Conference on, pages 163-168, Oct 2013.

[60] P. Ionela et al. A model predictive control framework for reliable microgrid energy management. International Journal of Electrical Power \& Energy Systems, 399 - 409, 2014.

[61] C. Cecati et al. Optimal operation of smart grids with demand side management. In Industrial Technology (ICIT), 2013 IEEE International Conference on, pages 2010-2015, Feb 2013.

[62] A. Hooshmand et al. A novel cost-aware multi-objective energy management method for microgrids. In Innovative Smart Grid Technologies (ISGT), 2013 IEEE PES, pages 1-6, Feb 2013.

[63] S. Manuela et al. Building-integrated microgrid: Advanced local energy management for forthcoming smart power grid communication. Energy and Buildings, 236 - 243, 2013.

[64] R. Roche et al. Algorithmes hybrides pour la gestion intelligente de l'énergie dans les smart grids. In Journées Francophones sur la planification, la décision et l'apprentissage pour le contrôle des systèmes - JFPDA 2012, page 14 p, May 2012.

[65] T. Logenthiran et al. Multi-agent system for market based microgrid operation in smart grid environment. Dept. of Elec. \& Comp. Science, National University of Singapore, 2011.

[66] D. El Nabouch et al. An agent-based approach for efficient energy management in the context of smart houses. In Highlights on Practical Applications of Agents and Multi-Agent Systems, volume 365, pages 375-386, 2013.

[67] P. Vytelingum et al. Agent-based micro-storage management for the smart grid. May 2010.

[68] S. Ramchurn et al. Agent-based homeostatic control for green energy in the smart grid. ACM Transactions on Intelligent Systems and Technology, 35:1-35:28, July 2011.

[69] J. Klaimi et al. An energy management approach for smart-grids using intelligent storage systems. In Digital Information and Communication Technology and its Applications (DICTAP), 2015 Fifth International Conference on, pages 26-31, April 2015.

[70] J. Klaimi et al. An agent-based approach for energy management in smart-grids. In Highlights of Practical Applications of Agents, Multi-Agent Systems, and Sustainability-The PAAMS Collection, pages 225-236. 2015.

[71] M. Ghamkhari et al. Energy and performance management of green data centers: A profit maximization approach. Smart Grid, IEEE Transactions on, 1017-1025, June 2013. 
[72] H. Insung et al. Cloud computing-based building energy management system with zigbee sensor network. In Innovative Mobile and Internet Services in Ubiquitous Computing (IMIS), 2012 Sixth International Conference on, pages 547-551, July 2012.

[73] M. E. El-hawary. The smart grid: state-of-the-art and future trends. Electric Power Components and Systems, 239-250, 2014.

\begin{abstract}
Authors
Joelle Klaimi received her Telecommunication Engineer degree from the Lebanese University- First Branch, Tripoli, Lebanon, in 2012. She also received her M2R in Medical Technology and Industrial Systems (TSMI) in 2012 from the Lebanese University, Doctoral school of sciences and technology. Currently, she is a $\mathrm{PhD}$ student at the Lebanese university, Lebanon and Troyes University of Technology, France. Her research interests include distributed systems, agent cooperation and energy efficiency.
\end{abstract}

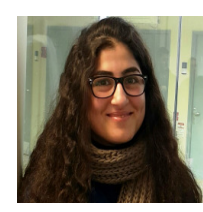

Rana RAHIM-AMOUD received with distinction her Computer science and Telecommunication Engineer degree from the Lebanese University - First Branch, Tripoli, Lebanon, in 2002. She then obtained her Master degree (DEA) in Networking and Telecommunication in 2003 from the USJ University and the Lebanese University, Beirut, Lebanon, and her PhD degree in January 2008 from the University of Technology of Troyes (UTT) - France. She was a postdoctoral researcher at the UTT from October 2008 to October 2009. She obtained her HDR (Habilitation à Diriger des Recherches) in 2016. She is currently Assistant professor at the Lebanese University. Her research interests include Multi-agent Systems, System management, Quality of Service, WSN Networks, IoT Networks, Smart Grids. She is author of more than 30 papers published in leading journals and conference proceedings. She is the General Chair of the New Generations of Networks Workshop (NGN). She is also TPC member for many international conferences and has served as a reviewer for a number of international journals and conferences.

Dr. Leila Merghem-Boulahia received an engineering degree in computer science from the University of Sétif, Algeria, in 1998, an M.S. degree in artificial intelligence and a $\mathrm{Ph} . \mathrm{D}$. in computer science from the University of Paris 6, France, in 2000 and 2003, respectively. She received the "Habilitation à diriger des recherches" degree in Computer Science from the University of Compiègne in 2010. She is an associate professor at the University of Technology of Troyes (UTT) in France still 2005. Her main research topics include multi-agent systems, quality of service management, autonomic networks, cognitive and sensor networks and smart grids. Dr. Merghem-Boulahia authored or co-authored more than 80 international journals and conference papers. She received the best paper award of the IFIP WMNC'2009 and GIIS'2013. She also acted as a TPC member of many conferences and workshops (IEEE Globecom, IEEE ICC, IEEE MASS...) and has served as a reviewer for internationally well-known journals (IEEE Communications letters, Communication Networks, International Journal of Network Management, Annals of Telecommunications).

Akil Jrad was born in Kalamoun, Lebanon, on September 4, 1970. He received the M. Sc. degree in physics from the Lebanese University, Tripoli, Lebanon in 1994, the Ph.D. degree in electronics from the University of Savoy, France, in 1999. From 1999 to 2001, he was with the Laboratory of Microwaves and Characterization, University of Savoy, France, where he was involved with the conception and realization of NLTL's for the generation and measurement of ultra-fast microwave signals and frequency multipliers. Currently he is a professor at the Lebanese University. He is also member of the laboratory of the Electronic Systems, Telecommunications and Networks (LaSTRe), EDST, Lebanese University, where his current research interests include nonlinear microwave and millimeter-wave circuit analysis and design. He is author of more than 50 papers published in leading journals and conference proceedings. He is TPC member for many international conferences and has served as a reviewer for a number of international journals and conferences. 